\title{
O MORFEMA DE GRAU: SUFIXO FLEXIONAL OU DERIVACIONAL?
}

Antônio José Sandmann

\section{Introdução:}

Através da presente exposição propomo-nos a lançar algumas luzes sobre a questão formulada no título acima: se o morfema de grau, tanto o aumentativo como o diminutivo dos substantivos ou o superlativo dos adjetivos - sem excluir o aumentativo e di minutivo, mais raro, dos adjetivos (bonito-bonitaso - bonitinho), o superlativo, raríssimo, dos substantivos (coisa - coisissima), nem o diminutivo, da linguagem familiar, dos advērbios (perto - pertinho), ou verbos (dormindo - dormindinho), ra ro também - $\bar{e}$ um sufixo flexional ou un sufixo derivacional, ou em outra terminologia, se se enquadra entre os afixos(sufixos)ou entre as flexöes (desinencias). Antes de mais nada diríamos, an tecipando o que mais tarde se pretende mostrar melhor, que a su fixação flexional é a aposição de morfemas e lexemas ( raízes ou radicais) para efeito de concordancia das palavras dentro do sintagmas, enquanto sufixação derivacional é a adjunçāo de morfemas a lexemas para a formação de novas palavras, diferentes, e de outra série paradigmática ou subparadigmática.

\section{Omorfema de grau na gramaticologia portuguesa:}

2.1 Para alcançar o que se pretende, poderíamos ver como a matéria foi considerada dentro da gramaticologia portuguesa, no que nos vemos, naturalmente, na contigência de considerar 134 
apenas alguns autores.

2.2 Eduardo Carlos Pereira, em sua "Gramática Expositiva" (ediçōes 12a., de 1921, e 92a., de 1954, pägs.60 e 79-80, res pectivamente), diz: "Estas oito categorias gramaticais classificam-se em dois grupos, quanto à flexāo, istoé, quanto à pro priedade de variarem ou näo em sua desinência para indicarem os acidentes da idéia por elas expressada. Esses acidentes são de grait, gênero, nümero, caso, modo, tempo e pessoa." Perdura aqui ainda a doutrina gramatical clássica, baseada na filosofia aristotēlica, de que os lexemas seriam substâncias que se apresentam sob diversas formas acidentais, as flexōes. As "oito categorias gramaticais" de que se fala, são o que hoje chamamos de classes de palavras,e onome categorias gramaticais se reserva agora ao que então se chamavam os acidentes. Do exposto e do trato que o autor da à matéria emoutras partes de sua obra, conclui-se que não fazia uma divisão clara entre sufixo flexional e sufixo derivacional, pois para ele a fiexão è "a propriedade de (as palavras) variarem em sua desinencia para indicarem os acidentes" e "o estudo da flexão compreende tambëm os sufixos derivativos". E o que mais interessa a presente estudo, istoé, a flexão de grau, esta se acha no mesmo rol das desinências de gênero, nümero, caso, modo, tempo e pessoa, e em outro rol estão os sufixos derivativos, também chamados flexöes.

2.3 Said Ali é o segundo autor que examinaremos sob o aspecto que nos interessa. E o Earemos através da "Gramātica His tórica da Língua Portuguesa" e da "Gramātica secundāria da Lín gua Portuguesa", Edições Melhoramentos, 1964. Diz-nos

Said 
Ali: "No exame das palavras verifica serem estas geralmente for madas de duas partes: o radical, parte mais ou menos estável e de significação prōpria, e afíxos, elementos variáveis, de significação relativa, isto é, de valor semantico somente na combinaçāo com o radical". E adiante: "Os sufixos, divididos em prefixos, sufixos, terminações e desinências, dão ao vocābulo a diversidade de formas ("Gramātica Histörica", päg. 53).

Afixos seriam todos os morfemas que, na economia da lingua, se juntam ao lexema para a formaçäo de novos vocábulos. No entanto, embora se depreenda da lição do autor sobre a formação das palavras ("Gramātica Secundāria", pāg. 107 e seguintes) que os prefixos e sufixos são os elementos com que se formam novas palavras por derivação - e nesse processo inclui o aumentativo e diminutivo dos substantivos e adjetivos, mas dele exclui o superlativo dos adjetivos - näo se obtēm uma idéia clara sobre o que sejam "terminações" e "desinências". Quando distingue o infinito pessoal do impessoal fala em infinito flexionado e desinência pessoal. Referindo-se ao piural e superla tivo dos adjetivos, refere-se a um sufixo-es e -issimo. o nore terminacāo é empregado tanto para os morfemas -ago, -aca -ay (aumentativos), -ote, -oîa, -acho (diminutivos), para o mor fema nominal - $a$ (feminino), cumo para os segmentos finais -es, de simples, -em, de virgem, -um de comum, etc. Todavia, apesar dessa falta de precisāo terminológica - percebe-se que fazia falta uma designação como morfema, aplicável a todas as uni dades minimas significativas - Said Ali distinguia claramente a sufixação derivacional da flexional, incluindo naquela os aumentativos e diminutivos de substantivos e adjetivos e excluin- 
do da mesma o superlativo "intensivo" sintético dos adjetivos.

2.4 Mansur Guérios, em "Português Ginasia1" (Editora Sarai va', 11a. edição, 1964), obra que, ostentando embora o título modesto de "ginasial", tem a mesma abrangência de tantas outras gramāticas ditas não seriadas, apresenta a matēria em anā 1 ise de modo muito claro e dentro, basicamente, daquilo que nos propomos a mostrar posteriormente. "Desinência é a termina çào de vocābulo ou de sufixo, que indica, nos substantivos e adjetivos, o gênero e o nümero, e, nos verbos, a pessoa, o nūmero, o tempo e o modo. Tambēm se chama flexão "(pāg. 321). 0 morfema de grau não estā incluído aí, pois, à päg. 206 e seguintes, onde se estuda a derivaçāo por prefixo e sufixo, estão incluídos os aumentativos e diminutivos dos substantivos, $\epsilon$, às pägs. 39,40 e 41, quando desenvolve o grau do adjetivo, admite grau aumentativo e diminutivo nos adjetivos (bonita bonitinha - bonitona, alto - altinho - altãol; alude à possibilidade de se formar o superlativo dos adjetivos por meio de prefixos: arquivetho, extrafino, revelho, sobreagudo, superfino, ultrademocrätico (veja-se o paralelismo entre superelegan te - prefixação - e elegantissimo - sufixaçāo - ), e dos adjetivos no grau superlativo diz textualmente: "superlativo absoluto sintético (uma só palavra, istoé, comos sufixos -íssimo, -imo, -érrimo) -altissimo, facilimo, celebérrimo, etc." Esta posição é exatamente a que Mattoso Câmara defende em "Estrutura da Língua Portuguesa" (Editora Vozes Limitada, 1970, pág. 71 e ss.). no cap. X "O Mecanismo da Flexão Portuguesa". Antes, porēm, de analisarmos a doutrina deste autor, vejamos ainda mais outras gramāticas para ver quão diferentes podem 
ser as afirmaçōes a respeito do assunto.

2.5 Hả uma gramática por aí, a "Gramática Metódica da Língua Portuguesa", de Napoleão Mendes de Almeida, cujo sucesso só pode ser devido ao despreparo e à falta de formaçāo linglís tica mais acurada de grande parte dos que se põen a ministrar aulas de língua nacional aos nossos alunos. No presente estudo temos por base a 13a. edição, 1961, da Editora Saraiva.

Depois de tanto progresso alcançado na análise morfológica de nosso idioma, lemos, na "Metódica", afirmaçöes como estas: "Dos poucos exemplos acima (macaco - macacão - macaquinino, homem - homenzarrão - homenzinho, muro - muratha -murinhol, vemos serem diversas as desinências, terminafões ou sufixos graduais". "Pois bem, possuímos em nosso idioma diversas desinên cias que, acrescentadas no radical dos substantivos, podem especificar o tamanho da coisa que eles designam" (pág. 117). "Duas são as flexões de grau do adjetivo: a comparativa e a superlativa. Dizendo: Pedroé estudioso, atribuímos ao indivíduo Pedro uma qualidade, expressa normalmente. Dizendo: Pedro $\vec{e}$ mais estudioso, reforçamos a qualidade, elevando-a a um mai or grau; o adjetivo passa para o grau comparativo. Eizendo, por ūltimo: Pedro é estudiosíssimo, reforçamos aindamais a qualidade, elevando-a ao último grau, ao grau mäximo, e o adjetivo, então, estā no grau superlativo" (päg. 134). Para Napoleão Mendes de Almeida tudo é flexão, até comparativos, sempre analíticos ou frásicos, como: tāo esperto como, mais esper to que, menos esperto que; ou o superlativo relativo, sempre analitico: o mais esperto; e o superlativo absoluto analitico: muito esperto. Bem sabemos que, para Hockett (vide o verbete 
flexão, do "Pequeno Dicionārio de Linguística Moderna", de Fran cisco da Silva Borba, 1971), a flexão pode ser por afixo ou frá sica. Exemplo daquela temos no ingles nearest e desta em most difficuzt. Mas aqui temos uma diferenciaçäo clara entre os dois processos e em Napoleão não se faz distinção.

o estudo do gênero dos substantivos, para citar outro exemplo, recebeu simplesmente a denominação flexão genérica, e debaixo deste título é estudado todo o capítulo da formação e indicação do gênero dos nomes substantivos em português: a) mediante desinéncia: filho - filha, doutor - doutora; b) mediante sufixo: barão - baronesa, heröi - heroina; c) mediante aposição do artigo: o artista - a artista; d) mediante locução: a cobra macho - a cobra fémea, o jacaré macho - o jacaré fémea ( o autor prefere a cobra macha - a cobra fémea, o jacré macho- o jacaré fêmeo) ou o macho da cobra - a fêmea da cobra;f) mediante heteronímia: homem - muliber, bode - cabra, etc. E poderiamos multiplicar os exemplos em que são baralhados os conceitos de desiéncia e sufixo ou do que chamaríamos, paramaior clareza, sufixo flexional e sufixo derivacional.

$2.6 \mathrm{Ja}$ em Portugal, segundo o "Compêndio de Gramática Portuguesa" (para o segundo ciclo do Ensino Liceal), de Josē Nunes de Figueiredo e Antônio Gomes Ferreira (Livraria Sá da Costa Editora, 3a. edição, 1968), temos uma distinção clara entre ambos os conceitos. Reza a obra dos professores-metodólogos de Coimbra e Lisboa: "A desinência é a letra ou letras que se juntam ao tema, para exprimir diversas noções acrescentadas à idéia por ele significada: leitor - Leitora(noçāo de feminino), leitor - Leitores (noção de nümero). As desinências, nos nomes, 
indicam o número e o gêneroe, no verbo, o número e a pessoa" (pāg. 88). Estranhamos na definição o "letra ou letras", mas apraz-nos ver que o morfema de grau foi excluido. Este, confor me os mesmos mestres, é sufixo: "Chama-se aumentativo a forma do substantivo que indica aumento; esta forma obtém-se com o acrescentamento dos sufixos:-apo (ricago, senhorago)..."(pág. 107). 0 mesmo é dito do morfema de diminutivo dos substantivos e do "superlativo absoluto simples" dos adjetivos. Em resumo, reservam eles o nome genérico de flexão aos morfemas de gênero, número e grau dos substantivos e adjetivos, e de número e pessoa dos verbos, sendo a flexão de grau um sufixo ( sufixo derivacional), e as demais, desinências (sufixos flexionais ou desinências).

2.7 Voltando ao Brasile atē bem perto de nös, temos "Gramática Construtural da Língua Portuguesa", de Eurico Back e Geraldo Mattos (Editora F.T.D., S.A., la. edição, 1972). Sem nos adentrarmos muito nos vários aspectos renovadores e válidos da doutrina desses mestres paranaenses, reportamo-nos ao capítulo 5o "Construtura do Vocábulo", analisando alguns itens que interessam ao presente estudo.

Defrontamo-nos, inicialmente, com uma classificação diferente dos morfemas. o que chamamos desufixos derivacionais, excetuando os de grau, constituem raizes substantivas, adjetivas ou verbais, segundo se aponham à direita do raio de menção (lexema) para formar substantivos, adjetivos ou verbos:pobre - pobr teza (pobre, raiz adjetiva, passa a raio de menção e -eza é a raiz substantiva, porque probrezaé substantivo gra ças ao morfema -eza, sendo este elemento, portanto, o eixo, o 
centro da palavra); Paraná - parana + ense (Paranáa, raiz substantiva, passa a raio de menção e -ense é a raiz adjetiva);sua$v e-s u a v+i z a+r$ (suave, raiz adjetiva, torna-se raio de mençäo, -iza é a raiz verbal e -r, sufixo (desinência). os morfemas, portanto, que podem ocupar o eixo (o sol ou centro) do vocäbulo ou o raio de menção sāo as raízes. Os demais raios são os afixos. Estes se subdividem em prefixos, quando antecedentes, e sufixos, quando consequentes. Os afixos chamam-se também flexões e são ditas flexões facultativas (o prefixo, também chä mado raio de declaração, e o sufixo de grau) ou obrigatórias (o gênero e o numero nos adjetivos, e pessoa "em algumas formas verbais").

Os ocupantes do raio de menção não são todos os nossos tradicionais prefixos gregos, latinos e vernáculos, mas tão só o "zero", morfema positivo, como em "zero"tmoral (adj.), por exem plo, o/dez-/ e seus alomorfes, morfema negativo, como em $i+$ moral, e o $/ a-l$, morfema neutro, de $a+$ moral, p. ex.o morfema de grau é sufixo de la. ordem porque precede o morfema de gêne ro (sufixo de 2 a. ordem), o qual é seguido, por sua vez, do de nümero (sufixo de $3 a$. ordem), e é facultativo porque sua ausência não é significativa: não há omorfema "zero" de grau. E é a este ponto que queríamos chegar no estudo do morfema de grau, segundo a "Gramātica Construtural". Tanto o morfema

de grau como os de gênero, número e pessoa seriam sufixos porque vếm após o eixo do vocábulo e porque com eles não se formariam palavras novas como sucede com as raízes substantivas, adjetivas e verbais: magno - magn+itude, gramätica-gramatiqu + ice, Lisboa - lisbo + eta, amarelo - amarel + ece + r. Em gramatica- 
gramatiquice, embora tenhamos dois nomes substantivos, os mesmes säo diferentes, tên sentido diferente, têm traços semānti cos diferentes, pertencendo, portanto, a séries subparadigmáti cas diversas.

Como bem observaram, no entanto, os autores da "Construtural", o morfema de graué facultativo; sua auséncia não é significativa, como é significativa a falta do-s no singular falava+"zero" (2ivpots = plural), ou na la. e 3a. pessoas do singular falavat"zero" (fajavats = 2 a. pessoa do singular) do pretérito imperfeito do indicativo, ou ainda a ausência do - $a$ no masculino doutor + "zero" Joutorta = feminino). E aqui nos parece que pouco divergem as posiçós assumidas por Mansur Gué rios ou Mattoso Câmara, por exemplo, e pela "Gramática Construtural". O sufixo derivacional e o sufixo flexional daqueles distinguem-se exatamente como se distinguem os ocupantes do morfema de grau e os ocupantes dos morfemas de gênero e nümero dos nomes e de pessoa dos verbos desta por serem facultativos uns e obrigatórios outros. Ou, em outros termos, Mansur Guérios e Mattoso Câmara nāo pōem o morfema de grau entre as desinências ou sufixos flexionais porque não são obrigatórios.

2.8 Se não, vejamos o que diz Mattoso Câmara no livro e ca pítulo já citados, às pägs. 71 e ss. Citando o gramático lati no Varräo (11 a.C. - 26 a.C.). diz liatoso Câmara que o mesmo "distinguia entre derivatio voluntaria, que cria novas palavras, e a derivatio naturalis, para indicar modalidades especí ficas de uma determinada palavra". A derivação é voluntária por não ser um sistema rígido, fechado. De saltar, por exemplo, posso formar saltitar, o que não se dá com pular e andar. 
Veja-se, para comparação, as formas verbais saltei, pulei e andet, das quais não possofugir se quiser expressar a pessoa que fala (la.pessoa do discurso), o tempo passado e o aspecto incon cluso. Por outro lado, de falar formo fala, de passar, passagem de preterir, preterifão, de esquecer, esquecimento, etc. A esta formação livre de substantivos a partir de raízes verbais compare-se a coerência e a rigidez das formas da 1 a. pessoa do singular do presente do indicativo dos mesmos verbos: pretir-o, pass-o, esquec-o, fal-o.

os diminutivos e aumentativos dos substantivos e o superlativo dos adjetivos, por sua vez, não são de emprego obrigatorio da parte do falante, pertencendo, em geral, mais à estilistica do que a gramática pelas conotações de apreço ou menosprezo que acrescentam. Observe-se, por exemplo, o emprego coloquial recen te da terminação-ërrimo (bacanérrimo, animadérrimo, elegantérrimo), alomorfe do sufixo de superlativo dos adjetivos, antes reservado só a certos adjetivos que tinham determinada terminaçāo em latim (célebre - celebérrimo,acre-acérrimo). A mesma liberdade não hä com o sufixo flexional. o contexto da frase diráa se devemos usar o plural ou o feminino de um adjetivo para fazê-lo concordar com o substantivo que determina, ou se o verbo está em determinado numero e pessoa para se adaptar ao sujeito da frase. Pela sufixação derivacional criam-se constan temente novos termos, amplia-se o léxico, pois que entre um vocábulo derivado e os demais vocābulos similares derivados há es se tipos de "relações abertas": quadrinizar (adaptar aos quai drinhos), globalizar, globalizante, globalizacão, problematicidade, essencialidade, presentificar, objetificasão são exem- 
plos colhidos de um recente artigo de crítica literäria. Näo há essa ampla possibilidade de formar vocábulos novos ou dar novamente vida aos mesmos para as necessidades da expressão com os sufixos flexionais. Estes são sēries fechadas. iāo se pode inovar. Não se pode acrescentar, por exemplo, uma desinên cia nova ao vocäbulo lobo ou ao verbo izvar.

Concluímos a análise do pensamento de latoso cāmara com a seguinte citação (pág. 73): ":ia realidade o que se tem com os superlativos é uma derivação possível em muitos adjetivos, como para os substantivos ha a possibilidade dos diminutivos e para alguns (não muitos) a dos aumentativos. Anote-se a propósito que o conceito semântico de grau abrange tanto os superlativos como os aumentativos e diminutivos. Por isso, otoniel Motta considerou aumentativos e diminutivos uma "flexäo" dos substantivos, pelo exemplo dos superlativos (Hotta), porque näo ousou considerar os superlativos uma derivação, como são muito logicamente considerados aumentativos e diminutivos por toda gente. Em outros termos. A expressão de grau nāo é um pro cesso flexional no portuguès, porque não é um mecanismo obriga törio e coerente, e não estabelece paradigmas exaustivos e de termos exclusivos entre si."

\section{Conclusão}

Nossa conclusão primeira seria que pouco há a acrescentar sobre o assunto, pois o que se tinha a dizer foi dito a propösito dos comentários sobre a doutrina dos vários autores. Restar-nos-ia, então, mais propriamente, um resumo de tudo que se disse. A sistemātica, a rigidez e a coerência do sufixo flexio nal de gênero e número dos nomes, e de nümero e pessoa, modo 
e tempo dos verbos, impede-nos de incluir nele o sufixo grau. Veja-se, para ilustração, a situação do artigo e do adje tivo nos sintagmas nominais seguintes: o heróico soldado, formosa donzela, os attos rédios, as delicadissimas damas, ou dos verbos, nos sintagmas oracionais: quero que vocé estude, $e$ queria que voca estudasse. Os adjetivos, subordinados aos subs tantivos que determinam, e em intima coesão com os mesmos, con cordam com eles em gênero e nümero. Os verbos, por sua vez, concordam todos com os seus sujeitos em número e pessoa e, além disso, os das oraçōes subordinadas estäo em correlação de tempo e modo com os das principais, o que também é uma forma de coesão. A esses fatos se compare o seguinte: Se alguém qui ser expressar, por exemplo, o extremo grau de velhice de alguém ou de alguma coisa, terá inumeros recursos à sua escolba: poderä dizer, v. g., muito velho, velhissimo, ultravelho, revetho, extravelho (propaganda de conhaque), supervelno, arquivelho, muitissimo velho, bastante velho, bastantissimo velho, tremendamente veitho, extremamente velho, velho velho, velhinho velhinho, velho a mais não poder, etc. sem esquecer que velho também admite o aumentativo velhasas (homem muito velho) ou velhão, e os diminutivos, de matizes semanticos variados: velhote, velhusco, velhustro e velninho (já citado).

De outra parte, se incluímos o sufixo de grau entre os sufixos derivacionais, ele näo deixa de ser um sufixo derivacional "sui generis", mormente o superlativo dos adjetivos. Expli camos: Com os sufixos derivacionais podemos, em geral, formar derivados que pertencem a outra classe de palavras: brasa (subst.)-brasil (adj.) - Brasil (subst.)-brasileiro ( subst. 
e adj.) - brasileirismo (subst.) - aorasileirar (verbo) - abrasizeiramento (subst). E mesmo que o derivado seja da mesma clas se de palavras, ele tem sentido diferente, tem traços semānticos muito distintos: caju (a fruta) - cajueiro (a planta), hóspede (a pessoa) - hospejaria (a casa que recebe o hóspede). Com o sufixo de grau, menos ainda com o superlativo do que com o aumentativo e diminutivo, as possibilidades de derivar, de "desviar", sāo bem menores. Fica-se sempre na mesma classe, indicando o menor ou maior tamanho ou a predicação em menor ou maior intensidade: sala - salinha, faca - facão, bonito - bonitinho - bonitão, beio - beiissimo, fácil - facilimo, escrever escrevinhar, saltar - saltitar, cedo - cedinho.

\section{Bibliografia Citada}

Mansur Guérios, Rosário Farani, "Português Ginasial", Editora Saraiva, S. Paulo, 11 a. edição, 1964.

ilattoso Cámara Jr., Joaquim, "Estrutura da Língua Portuguesa", Editora Vozes Limitada, Petrópolis, 2a. edição, 1970. Back, Eurico e llattos, Geraldo, "Gramātica Construtural da Língua Portuguesa", Editora F.T.D. S.A., Säo Pau1o, la. edi ção, 1972 .

Percira, Eduardo Carlos, "Gramática Expositiva": a) Seção de Obras de "O Estado de São Paulo", São Paulo, 12a. ediçäo, 1921; b) Companhia Editora Nacional, São Paulo, Y2a. edição, 1954 .

Said Ali, Manuel de, "Gramática Histōrica da Língua Portuguesa", Ediçōes Melhoramentos, Säo Paulo, 1964. 
Said Ali, Manuel de, "Gramática Secundäria da Língua Portuguesa", Edições lel lhoramentos, São Paulo, 1964.

Mendes de Almeida, Napoleão, "Gramática Metódica da Língua Por tuguesa", Edição Saraiva, São Paulo, 13a. edição, 1961. Figueiredo, José Nunes de, e Ferreira, Antônio Gomes, "Compêndio de Gramática Portuguesa", Livraria Sá da costa Editora, Lisboa, 3a. edição, 1968 . 